\title{
Impact of Aging Effect and Heat Treatment on the Tensile Properties of PLA (Poly Lactic Acid) Printed Parts
}

\author{
MOHAMMAD SAKIB HASAN ${ }^{1} *$, TONI IVANOV ${ }^{1}$, MILOS VORKAPIC ${ }^{2}$, \\ ALEKSANDAR SIMONOVIC ${ }^{1}$, DAVID DAOU ${ }^{1}$, ALEKSANDAR KOVACEVIC ${ }^{1}$, \\ ALEKSA MILOVANOVIC ${ }^{3}$ \\ ${ }^{1}$ University of Belgrade, Faculty of Mechanical Engineering, Department of Aerospace Engineering, Kraljice Marije 16, \\ 11000 Belgrade, Republic of Serbia. \\ ${ }^{2}$ University of Belgrade, Institute of Chemistry, Technology and Metallurgy - Centre for Microelectronic Technology, \\ Njegoseva 12, 11000 Belgrade, Republic of Serbia. \\ ${ }^{3}$ University of Belgrade, Innovation Centre of the Faculty of Mechanical Engineering, Kraljice Marije 16, 11000 Belgrade, \\ Republic of Serbia
}

Abstract: Rapid innovations in 3D printing technology have allowed highly complex parts to be manufactured quickly and easily, particularly for prototyping purposes. Fused Deposition Modeling of thermoplastic materials is one of the most commonly used techniques in three-dimensional (3D) printing. The major aim of Fused Deposition Modeling (FDM) is to design and manufacture usable parts for fields such as engineering and medicine. Therefore, it is essential to investigate the mechanical properties of such FDM processed structures. One of the most commonly used materials currently on the market is Polylactic Acid (PLA). The main purpose of this paper is to investigate the effects of aging and heat treatment on the tensile properties of PLA printed test specimens. The tensile properties of parts manufactured by the $3 D$ printer are influenced by various parameters such as extrusion temperature, infill density, building direction, layer height, etc. A total of 96 specimens were built by altering building orientation and layer height to estimate and compare the tensile properties of the printed parts. To investigate the aging effect, 30 of 96 specimens were printed 6 months before the tensile experiment. Half of both aged and new specimens were cured in an oven at $57.5\left[{ }^{\circ} \mathrm{C}\right]$ for 3 hours while the other half endured no heat treatment. After the performed measurement, it can be concluded that heat treatment generally improves structural strength of the printed parts, while aging decreases it. However, these effects are highly dependent on the layer thickness and printing quality. The tensile test is conducted according to the ASTM D638 standard. The fractured samples were further characterized using an electron microscope.

Keywords: Aging Effect, Heat Treatment, PLA, 3D Printeing, Tensile Properties.

\section{Introduction}

Fused deposition modeling (FDM) is one of the most used methods in additive manufacturing (AM) or rapid prototyping (RP) technology. Additive manufacturing was first described by Charles Hull in 1986 in a process known as Stereolithography (SLA). Rapid prototyping has been widely used in different industries like aerospace, construction, prototyping and biomechanics. For the last 10 years, the aerospace industry has been one of the top sectors leading the AM market. Today, $18.2 \%$ of the revenue in the AM industry is received from the aerospace industry [1]. The FDM method consists of building parts with a thermoplastic filament such as PLA, ABS, etc. which is heated up to a certain temperature then extruded via a small nozzle to model the 3D part [2]. This additive manufacturing technique forms a part with a certain accuracy from a suitable digital format (e.g., stereolithographic (STL)) which is fused into many layers to obtain a desired thickness by generating and following a readable G-code that instructs the numerically controlled printer to enable the printing operation. Since its introduction this technology has been growing rapidly.

\footnotetext{
*email:d41-2017@studenti.mas.bg.ac.rs
} 
Nowadays, there is a large amount of research being conducted on the FDM method to alleviate the manufacturing grade and likewise increase the quality of end use products. This method is reliable, affordable and considerably minimizes waste of both time and materials $[3,4]$.

Acrylonitrile butadiene styrene (ABS) and polylactic acid (PLA) filaments are the commonly used materials in the FDM printing process. Nevertheless, this work is oriented towards parts made specifically with PLA. One must take into account that these polymers have tremendous advantages since they are naturally degradable when disposed in the environment. They are cheap, affordable and efficient in producing specimens that will undergo various tests before manufacturing the real part. Although there are significant advantages of these filaments, many researches have conducted and noted some drawbacks. Researchers from [5] noticed, that air gap, raster orientation and phase change of the polymer material after deposition cause weak interlayer bonding and remarkably high porosity, which result in reducing the load-bearing area. These pure thermoplastic printed parts lack mechanical strength, resulting in their limited use in practical applications. Therefore, adding reinforced materials such as carbon fiber can yield fiber reinforced plastic composite with a significant increase in strength, stiffness, and Young's modulus, while enhancing the thermal conductivity as well [6]. Some researchers focused on only one processing parameter such as raster angle [7] while [8] focused on the effects of infill density, extrusion temperature, raster angle and layer thickness on the mechanical properties of 3D printed materials. The influence of infill parameters on the tensile behavior is presented in [9]. Investigation of the effect of different layer thickness and raster angle on the mechanical properties of 3D-printed polyether-ether-ketone (PEEK) and a comparative mechanical study between PEEK and ABS was performed in [10]. Reference [11] investigated the influence of infill density and deposition angle on the tensile behavior of pure PLA in comparison with PLA- based composite. Reference [12] focused on the effect of annealing time and print orientation on 3D printed materials.

A total of 96 samples were produced with varying layer height and raster angle. Specimen dimensions were $175 \times 20 \times 3 \mathrm{~mm}$ according to ASTM D638. To see the aging effect of PLA, 36 specimens were printed 6 months before the experiment. The first set consisted of 6 specimens with line direction of both shell and infill [0/90]. The second and third sets were made of 6 specimens as well with the line direction of the infill and shell being [-45/45] for the second, and [0/-30/30/-60/60/90] for the third. Layer height for all 3 sets was kept at $0.3 \mathrm{~mm}$ for the first batch. The second batch consisted with three sets as well with the same orientations as the first batch but with a different layer height of $0.1 \mathrm{~mm}$. This layer height was considered in order to gain a better understanding effect of layer thickness on the mechanical behavior. Similarly, 60 new specimens were manufactured before the experiment where each set was composed of 10 specimens. Half of each set were cured in oven at $57.5\left[{ }^{\circ} \mathrm{C}\right]$ for $3 \mathrm{~h}$. The experimental results obtained from the tensile testing machine were then analyzed and discussed.

\section{Materials and methods}

This paper aims to examine the tensile properties of PLA specimens printed with different layer height and raster angles as well as the influence of aging and heat treatment on the tensile properties. Project workflow started with the selection of material. Sample preparation was in the second stage of our study and finally, the mechanical characteristics of printed parts were obtained in the experimental phase. Figure 1 illustrates the methodology of our research. 


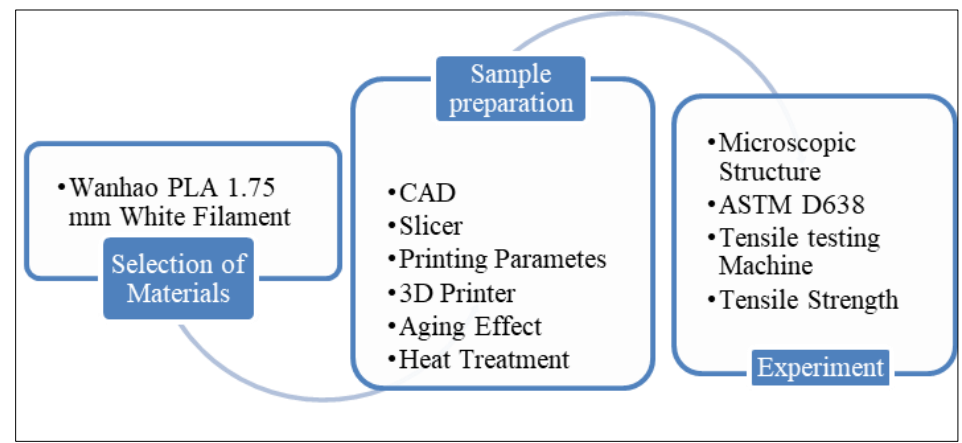

Figure 1. Workflow of the project

\subsection{Selection of material}

Wanhao PLA white filament with diameter of $1.75[\mathrm{~mm}]$ was used to print all the samples. The recommended printing characteristics of the PLA filament are shown in Table 1 and are specified by the manufacturer.

Table 1. Printing chracteristics of the commercially available Wanhao

PLA $1.75 \mathrm{~mm}$ white filament

\begin{tabular}{ccc}
\hline Nozzle temperature $\left[{ }^{\circ} \mathrm{C}\right]$ & Bed temperature $\left[{ }^{\circ} \mathrm{C}\right]$ & Density $\left[\mathrm{g} / \mathrm{cm}^{3}\right]$ \\
\hline $190-225$ & $50-60$ & 1.31 \\
\hline
\end{tabular}

\subsection{Sample preparation}

Specimens were modelled in accordance with the American Society for Testing and Materials ASTM D638 standard for plastic tensile testing [13]. The 3D printing parameters considered in this paper were the layer thickness and printing orientation or raster angle. Figure 2 points out the dimensions of the designed specimen.

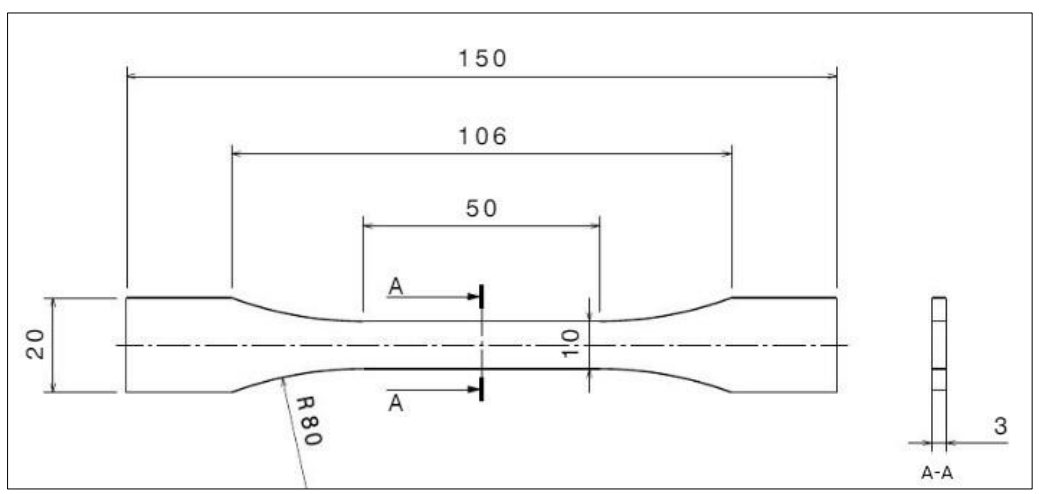

Figure 2. Dimensions of specimens (units are given in [mm])

Thus, a set of bone-shaped specimens, with a thickness of $3[\mathrm{~mm}]$ and initial distance between grips of 106 [mm] was considered. The CAD designed model was converted to a STL file format after which the printing parameters were set in a slicing software.

For the purpose of the setting the printing parameters and tool path calculation the free slicer Ultimaker Cura 3.1.0 was used. Ultimaker Cura is one of the world's most popular 3D printing software and offers over 400 settings for granular control [14]. Figure 3 presents the interface of the Ultimaker Cura 3.1.0 with a three-dimensional view of the model. 


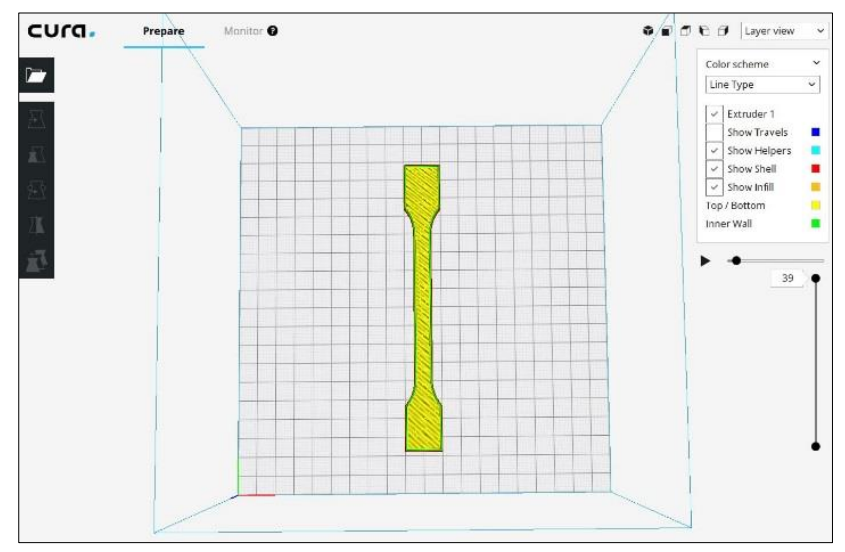

Figure 3. Interface of Ultimaker Cura 3.1.0

Printing parameters such as bed temperature $\left(60\left[{ }^{\circ} \mathrm{C}\right]\right)$, nozzle temperature $\left(215\left[{ }^{\circ} \mathrm{C}\right]\right)$, infill density $(100[\%])$ and printing speed $(60[\mathrm{~mm} / \mathrm{s}])$ were set identical for every specimen. The layer thickness of the first batch was kept at $0.3[\mathrm{~mm}]$ whilst for the second batch it was reduced to $0.1[\mathrm{~mm}]$. The wall thickness was $1.2[\mathrm{~mm}]$ in both batches and the top and bottom shell orientation was identical to the infill printing orientation. Table 2 shows the main printing parameters considered. The average masses were measured by using a precision digital scale.

Table 2. Main printing parameters

\begin{tabular}{|c|c|c|c|c|}
\hline Specimen number & $\begin{array}{l}\text { Layer Height } \\
{[\mathrm{mm}]}\end{array}$ & Raster angle $\left[{ }^{\circ}\right]$ & $\begin{array}{c}\text { Heat treatment } \\
{[\text { Yes/ No] }}\end{array}$ & Average mass [g] \\
\hline \multicolumn{5}{|c|}{ Aged Samples (36) } \\
\hline $1.1-$ & 0.1 & $45 /-45$ & \multirow{6}{*}{ zo } & 6.67 \\
\hline $2.1-2.3$ & 0.1 & $0 / 90$ & & 6.67 \\
\hline $3.1-3.3$ & 0.1 & $0 /-30 / 30 /-60 / 60 / 90$ & & 6.33 \\
\hline $4.1-4.3$ & 0.3 & $45 /-45$ & & 5.66 \\
\hline $5.1-5.3$ & 0.3 & $0 / 90$ & & 6.33 \\
\hline $6.1-6.3$ & 0.3 & $0 /-30 / 30 / 60 /-60 / 90$ & & 5.66 \\
\hline $7.1-7.3$ & 0.1 & $45 /-45$ & \multirow{6}{*}{$\stackrel{\Delta}{\infty}$} & 7.00 \\
\hline $8.1-8.3$ & 0.1 & $0 / 90$ & & 6.67 \\
\hline $9.1-9.3$ & 0.1 & $0 /-30 / 30 /-60 / 60 / 90$ & & 7.00 \\
\hline $10.1-10.3$ & 0.3 & $45 /-45$ & & 6.33 \\
\hline $11.1-11.3$ & 0.3 & $0 / 90$ & & 6.33 \\
\hline $12.1-12.3$ & 0.3 & $0 /-30 / 30 / 60 /-60 / 90$ & & 6.00 \\
\hline \multicolumn{5}{|c|}{ New Samples (60) } \\
\hline $13.1-13.5$ & 0.1 & $45 /-45$ & \multirow{6}{*}{$\stackrel{\circ}{z}$} & 7.40 \\
\hline $14.1-14.5$ & 0.1 & $0 / 90$ & & 7.00 \\
\hline $15.1-15.5$ & 0.1 & $0 /-30 / 30 /-60 / 60 / 90$ & & 7.40 \\
\hline $16.1-16.5$ & 0.3 & $45 /-45$ & & 6.60 \\
\hline $17.1-17.5$ & 0.3 & $0 / 90$ & & 6.80 \\
\hline $18.1-18.5$ & 0.3 & $0 /-30 / 30 / 60 /-60 / 90$ & & 6.80 \\
\hline $19.1-19.5$ & 0.1 & $45 /-45$ & \multirow{6}{*}{$\stackrel{0}{\nu}$} & 7.40 \\
\hline $20.1-20.5$ & 0.1 & $0 / 90$ & & 7.00 \\
\hline $21.1-21.5$ & 0.1 & $0 /-30 / 30 /-60 / 60 / 90$ & & 7.80 \\
\hline $22.1-22.5$ & 0.3 & $45 /-45$ & & 6.60 \\
\hline $23.1-23.5$ & 0.3 & $0 / 90$ & & 6.80 \\
\hline $24.1-24.5$ & 0.3 & $0 /-30 / 30 / 60 /-60 / 90$ & & 7.00 \\
\hline
\end{tabular}


The specimens were printed on a Wanhao duplicator i3 printer. Figure 4 illustrates the 3D printing process.

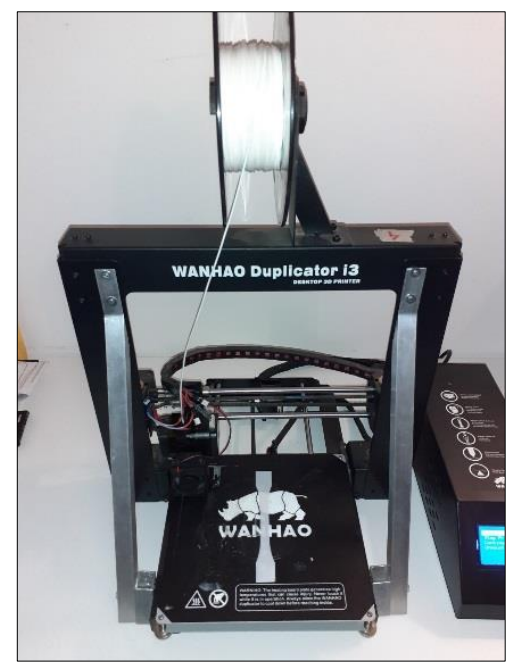

Figure 4. 3D printer WANHAO Duplicator i3

To observe the aging effect, we printed another 60 specimens 6 months after printing the first 36 samples. The initial 36 samples were stored at room temperature $\left(23.5-27\left[{ }^{\circ} \mathrm{C}\right]\right)$ for 6 months with humidity level between $30-50 \%$. Half of the samples of both aged and new sets were put into an oven immediately after printing where oven temperature was kept at $57.5\left[{ }^{\circ} \mathrm{C}\right]$ with a variant of $+/-0.5\left[{ }^{\circ} \mathrm{C}\right]$ for about $3 \mathrm{~h}$ [15]. The ambient temperature was $26.50\left[{ }^{\circ} \mathrm{C}\right]$ while atmospheric pressure was 1003 mbar. The oven temperature was monitored with a mercury thermometer- TESTO 735-2 with a Pt-100 probe as a temperature gauge. The main purpose of curing some of the samples was to observe the annealing characteristics of the PLA filament. Figure 5 shows the oven and the thermometer used for the heat treatment.

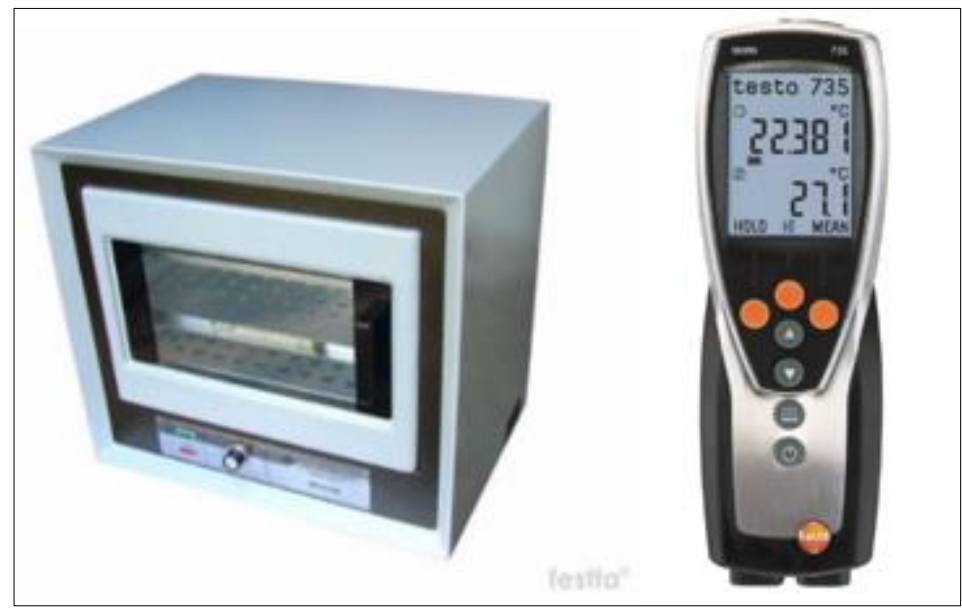

Figure 5. Oven and thermometer used for the heat treatment $[15,16]$

\subsection{Experiment}

After manufacturing the specimens, tensile tests of aged and new specimens were performed on the Shimadzu AGS-X Series universal testing machine which has a load capacity of up to $100 \mathrm{kN}$. To obtain valid results, calibration of the entire system was carefully performed. Each specimen was tightened by non-shift wedge grips. During the test procedure testing speed was set to $5 \mathrm{~mm} / \mathrm{min}$ in compliance with ASTM D638. The real-time data recorded during the experiments were load, displacement and time. Mechanical properties like Young's modulus of elasticity and maximum tensile strength were later 
calculated using the recorded data. Figure 6 represents the tensile testing machine and specimens after the tensile test.

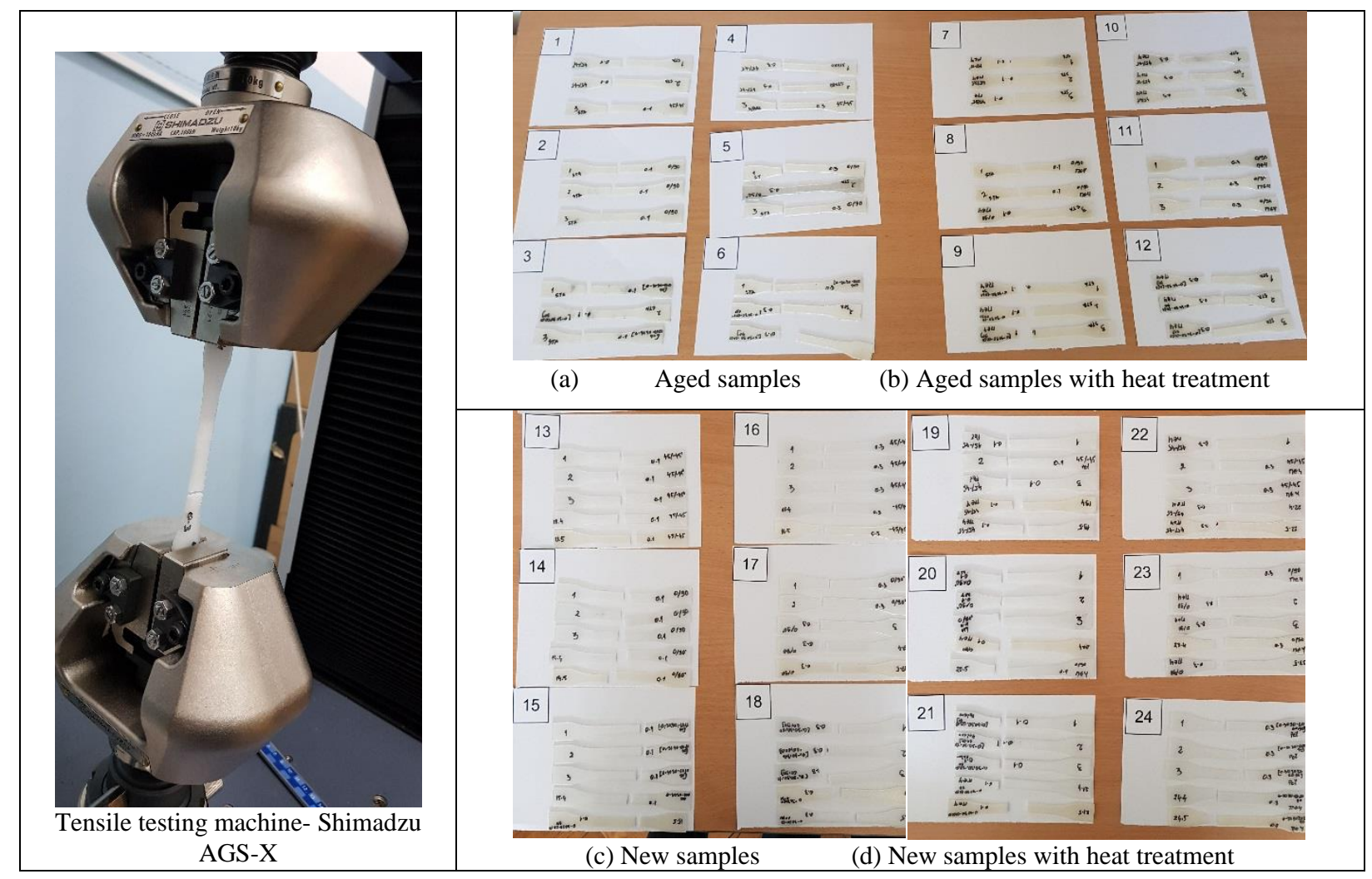

Figure 6. 3D printed samples after tensile testing

The Trapezium Lite X software tool was used for the analysis of the results. Figure 6 shows the Trapezium software and the force- displacement diagram obtained from it for one of the test specimens.
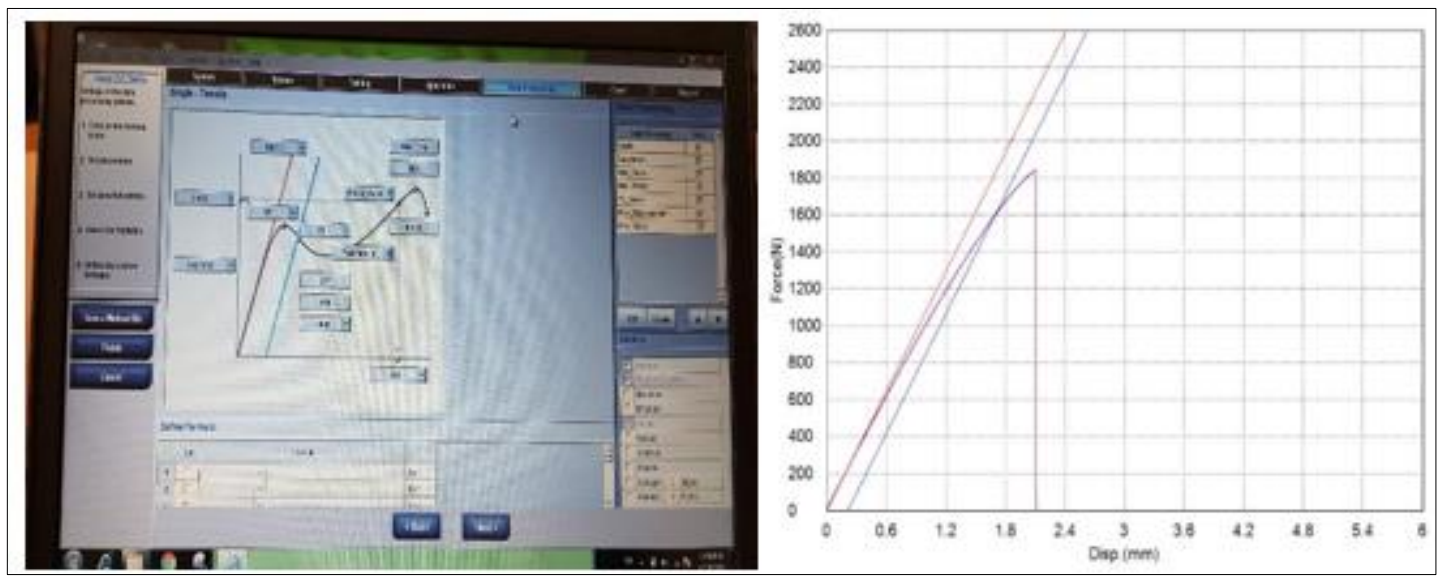

Figure 7. Trapezium-X software and the resulting force- displacement diagram obtained from the software

\section{Results and discussions}

\subsection{Microscopic structure}

Four samples were observed on an electron microscope Motic AE-2000 MET, (Figure 8). No special preparaitons were required before testing. 


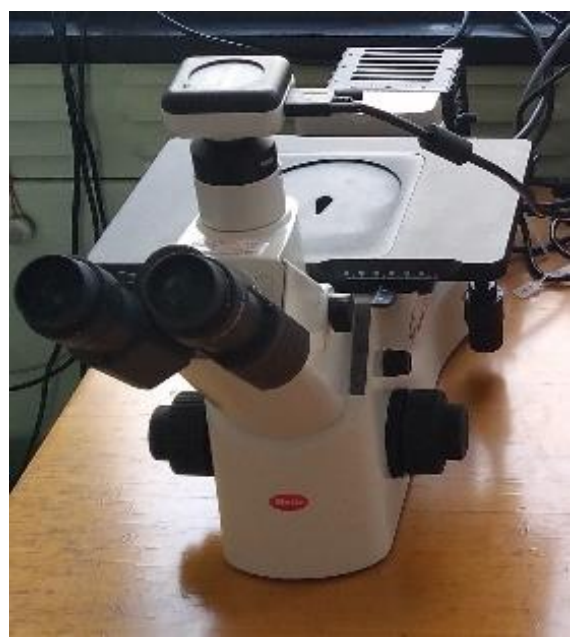

Figure 8. Electron Microscope Motic AE-2000 MET

By analyzing the surfaces of the samples, irregularities in the quality of the production of layers were identified. In the first sample, the layer thickness and infill orientation were kept at $0.1[\mathrm{~mm}]$ and $+45 /-$ $45\left[^{\circ}\right]$ respectively. Figure 9 shows the filament movement lines $(F)$ as well as the existence of furrows formed by the nozzle $(\mathrm{N})$. The red arrows show that there is a permanent furrow. That indicates that there was no uniform adhesion of the layers in the XY plane, (Figure 9). Damage to the fabrication of the layer line has occurred due to the rapid movement of the nozzle. On the other hand, the high temperature of the nozzle further burns the surface and thus weakens the bonds in the polymer which causes brittle and loose structure. Generally, the nozzle was constantly in contact with the material and therefore has been mechanically damaged over time. The reason for the occurrence of cracks can be justified by the existence of certain irregularities in filament cooling after the nozzle passage.

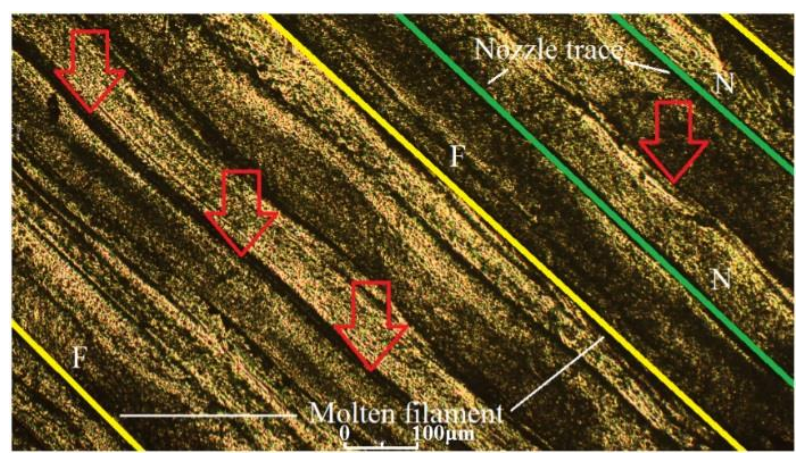

Figure 9. Microscopic view of a specimen (Layer height $0.1[\mathrm{~mm}]$; Raster angle $45 /-45\left[^{\circ}\right]$ )

Layer thickness and raster angle for the second sample were $0.1[\mathrm{~mm}]$ and $0 / 90\left[^{\circ}\right]$ respectively. Red arrows in figure 10 indicate that there is an irregularity in the printing process. In the upper half of the image, stretching of the formed molten lines was present due to high speed printing. The bottom half of the image shows that there has been a material accumulation. The molten filament cooled irregularly and joined with the previous layer. This happened due to the uneven material cooling at ambient temperature because the system was not isolated from the environment. When the PLA is being cooled continuously and evenly, better print quality could be obtained. 


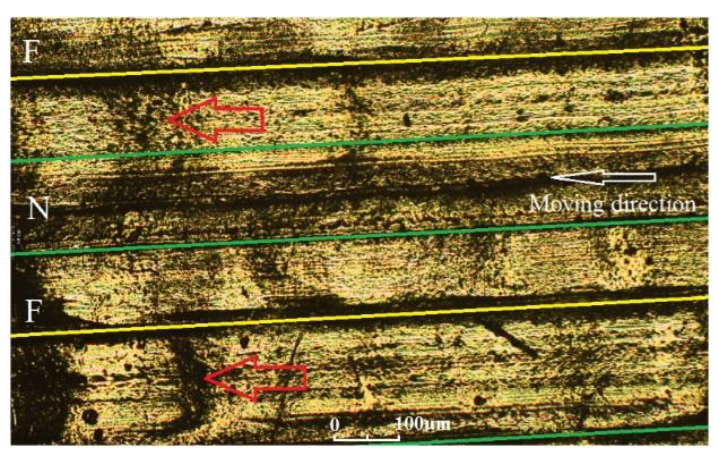

Figure 10. Microscopic view of a specimen

(Layer height $0.1[\mathrm{~mm}]$; Raster angle 0/90 $\left[^{\circ}\right]$ )

\subsection{Tensile properties}

As previously mentioned, a total of 96 samples were printed from which 36 were six months old and 60 were new. Half of the samples from both aged and new batches were subjected to heat treatment in an oven. Those 96 tested samples can be categorized into six groups or combinations. Combinations were made by varying raster angle and layer height to see the effect of heat treatment (HT) on new and aged specimens. The following 6 tables show the average values and standard deviations (SD) for the maximum force, maximum tensile stress and maximum displacement of the specimens.

Table 3. Average value of the main parameters in Combination 1 (Raster angle 45/-45, Layer Height $0.1 \mathrm{~mm}$ )

\begin{tabular}{|c|c|c|c|c|c|}
\hline & Specimens & Max Force $[\mathrm{N}]$ & $\begin{array}{c}\text { Max Tensile Stress } \\
{[\mathrm{MPa}]}\end{array}$ & $\begin{array}{l}\text { Max Disp. } \\
{[\mathrm{mm}]}\end{array}$ & $\begin{array}{c}\text { Young's Modulus } \\
\text { [GPa] }\end{array}$ \\
\hline Aged & $1.1-1.3$ & 1507.72 & 50.26 & 3.685 & 3.164 \\
\hline \multicolumn{2}{|c|}{ Standard Deviation } & 22.24 & 0.74 & 0.435 & 0.043 \\
\hline Aged with HT & $7.1-7.3$ & 1655.01 & 55.17 & 3.841 & 3.318 \\
\hline \multicolumn{2}{|c|}{ Standard Deviation } & 14.37 & 0.48 & 0.851 & 0.055 \\
\hline New & $13.1-13.5$ & 1581.71 & 52.72 & 3.027 & 3.416 \\
\hline \multicolumn{2}{|c|}{ Standard Deviation } & 71.98 & 2.39 & 0.271 & 0.033 \\
\hline New with HT & $19.1-19.5$ & 1607.85 & 53.59 & 3.021 & 3.300 \\
\hline \multicolumn{2}{|c|}{ Standard Deviation } & 50.07 & 1.66 & 0.107 & 0.046 \\
\hline
\end{tabular}

Table 4. Average value of the main parameters in Combination 2

(Raster angle 0/90, Layer Height $0.1 \mathrm{~mm}$ )

\begin{tabular}{|c|c|c|c|c|c|}
\hline & Specimens & Max Force $[\mathrm{N}]$ & $\begin{array}{c}\text { Max Tensile Stress } \\
{[\mathrm{MPa}]}\end{array}$ & Max Disp. [mm] & $\begin{array}{c}\text { Young's Modulus } \\
\text { [GPa] }\end{array}$ \\
\hline Aged & $2.1-2.3$ & 1439.34 & 47.97 & 2.127 & 3.143 \\
\hline \multicolumn{2}{|c|}{ Standard Deviation } & 8.06 & 0.26 & 0.085 & 0.013 \\
\hline Aged with HT & $8.1-8.3$ & 1549.53 & 51.65 & 2.258 & 2.905 \\
\hline \multicolumn{2}{|c|}{ Standard Deviation } & 7.72 & 0.26 & 0.052 & 0.106 \\
\hline New & $14.1-14.5$ & 1577.78 & 52.59 & 2.308 & 3.331 \\
\hline \multicolumn{2}{|c|}{ Standard Deviation } & 117.37 & 3.91 & 0.116 & 0.267 \\
\hline New with HT & $20.1-20.5$ & 1574.20 & 52.47 & 2.370 & 3.149 \\
\hline \multicolumn{2}{|c|}{ Standard Deviation } & 33.68 & 1.12 & 0.129 & 0.097 \\
\hline
\end{tabular}


Table 5. Average value of the main parameters in Combination 3 (Raster angle 0/30/-30/-60/60/90, Layer Height 0.1)

\begin{tabular}{|c|c|c|c|c|c|}
\hline & Specimens & Max Force $[\mathrm{N}]$ & $\begin{array}{c}\text { Max Tensile Stress } \\
{[\mathrm{MPa}]}\end{array}$ & Max Disp. [mm] & $\begin{array}{c}\text { Young's Modulus } \\
\text { [GPa] }\end{array}$ \\
\hline Aged & $3.1-3.3$ & 1422.09 & 47.40 & 2.874 & 2.944 \\
\hline \multicolumn{2}{|c|}{ Standard Deviation } & 28.76 & 0.95 & 0.282 & 0.007 \\
\hline Aged with HT & $9.1-9.3$ & 1683.84 & 56.12 & 2.804 & 3.337 \\
\hline \multicolumn{2}{|c|}{ Standard Deviation } & 49.35 & 1.64 & 0.072 & 0.077 \\
\hline New & $15.1-15.5$ & 1548.91 & 51.63 & 2.702 & 3.327 \\
\hline \multicolumn{2}{|c|}{ Standard Deviation } & 93.24 & 3.11 & 0.281 & 0.269 \\
\hline New with HT & $21.1-21.5$ & 1686.34 & 56.21 & 2.718 & 3.430 \\
\hline \multicolumn{2}{|c|}{ Standard Deviation } & 43.20 & 1.44 & 0.396 & 0.156 \\
\hline
\end{tabular}

Table 6. Average value of the main parameters in Combination 4 (Raster angle 45/-45, Layer Height $0.3 \mathrm{~mm}$ )

\begin{tabular}{cccccc}
\hline & Specimens & Max Force [N] & $\begin{array}{c}\text { Max Tensile Stress } \\
{[\mathrm{MPa}]}\end{array}$ & Max Disp. [mm] & $\begin{array}{c}\text { Young's Modulus } \\
{[\mathrm{GPa}]}\end{array}$ \\
\hline Aged & $4.1-4.3$ & 1126.08 & 37.54 & 2.637 & 2.586 \\
\hline Standard Deviation & 48.07 & 1.60 & 0.274 & 0.037 \\
\hline Aged with HT & $10.1-10.3$ & 1157.19 & 38.57 & 2.570 & 2.648 \\
\hline Standard Deviation & 113.50 & 3.78 & 0.050 & 0.182 \\
\hline New & $16.1-16.4$ & 1428.21 & 47.61 & 2.752 & 3.058 \\
\hline Standard Deviation & 23.32 & 0.78 & 0.490 & 0.014 \\
\hline New with HT & 1478.23 & 49.27 & 2.771 & 2.770 \\
\hline \multicolumn{2}{l}{ Standard Deviation } & 44.41 & 1.48 & 0.251 & 0.251 \\
\hline
\end{tabular}

Table 7. Average value of the main parameters in Combination 5 (Raster angle 0/90, Layer Height $0.3 \mathrm{~mm}$ )

\begin{tabular}{|c|c|c|c|c|c|}
\hline & Specimens & Max Force $[\mathrm{N}]$ & $\begin{array}{c}\text { Max Tensile Stress } \\
{[\mathrm{MPa}]}\end{array}$ & Max Disp. [mm] & $\begin{array}{c}\text { Young's Modulus } \\
\text { [GPa] }\end{array}$ \\
\hline Aged & $5.1-5.3$ & 1261.03 & 42.03 & 2.138 & 2.883 \\
\hline \multicolumn{2}{|c|}{ Standard Deviation } & 39.14 & 1.30 & 0.02 & 0.077 \\
\hline Aged with HT & $11.1-11.3$ & 1243.23 & 41.44 & 2.096 & 2.842 \\
\hline \multicolumn{2}{|c|}{ Standard Deviation } & 74.65 & 2.49 & 0.055 & 0.160 \\
\hline New & $17.1-17.4$ & 1503.26 & 50.11 & 2.463 & 2.46 \\
\hline \multicolumn{2}{|c|}{ Standard Deviation } & 92.25 & 3.08 & 0.283 & 0.147 \\
\hline New with HT & $23.1-23.4$ & 1568.94 & 52.30 & 2.326 & 3.252 \\
\hline \multicolumn{2}{|c|}{ Standard Deviation } & 42.97 & 1.43 & 0.228 & 0.065 \\
\hline
\end{tabular}

Table 8. Average value of the main parameters in Combination 6 (Raster angle 0/30/-30/-60/60/90, Layer Height $0.3 \mathrm{~mm}$ )

\begin{tabular}{|c|c|c|c|c|c|}
\hline & Specimens & Max Force $[\mathrm{N}]$ & $\begin{array}{c}\text { Max Tensile Stress } \\
{[\mathrm{MPa}]}\end{array}$ & Max Disp. [mm] & $\begin{array}{c}\text { Young's Modulus } \\
\text { [GPa }]\end{array}$ \\
\hline Aged & $6.1-6.3$ & 1055.97 & 35.20 & 2.470 & 2.456 \\
\hline \multicolumn{2}{|c|}{ Standard Deviation } & 28.04 & 0.93 & 0.132 & 0.064 \\
\hline Aged with HT & $12.1-12.3$ & 1053.89 & 35.13 & 2.232 & 2.503 \\
\hline \multicolumn{2}{|c|}{ Standard Deviation } & 16.54 & 0.55 & 0.179 & 0.058 \\
\hline New & $18.1-18.4$ & 1528.71 & 50.95 & 2.648 & 3.229 \\
\hline \multicolumn{2}{|c|}{ Standard Deviation } & 87.79 & 2.92 & 0.170 & 0.094 \\
\hline New with HT & $24.1-24.4$ & 1619.55 & 53.98 & 2.579 & 3.231 \\
\hline \multicolumn{2}{|c|}{ Standard Deviation } & 14.62 & 0.49 & 0.284 & 0.032 \\
\hline
\end{tabular}




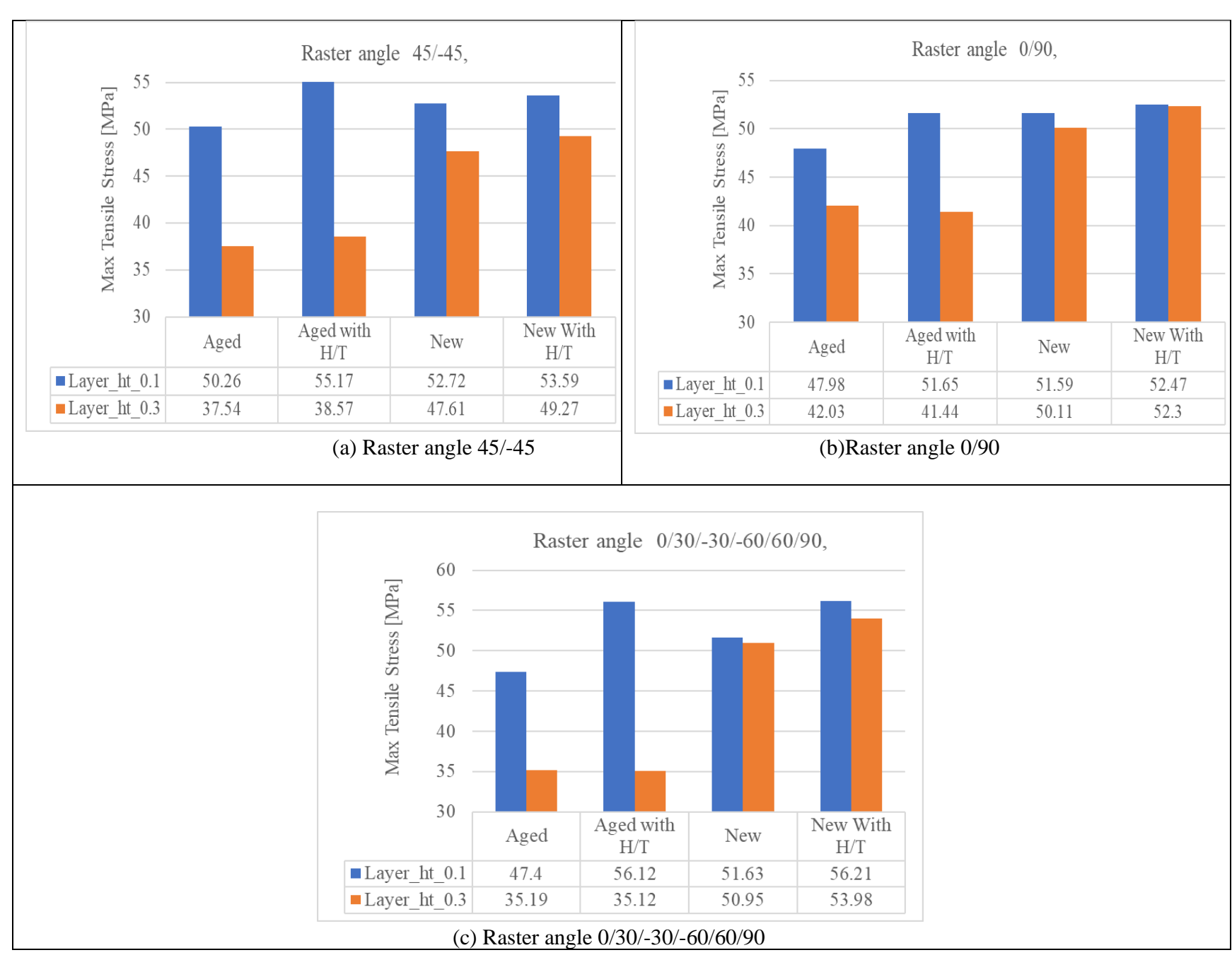

Figure 11. Average values of the maximum tensile stress for various raster angle

As can be seen in Tables (3-8) and on Figure 11 the mechanical properties of the PLA material generally degrade with aging. It can be seen that the degradation process is much more intensive for the specimens printed with $0.3[\mathrm{~mm}]$ layer thickness. This is probably due to the fact that there is a lot more "air gap" inside these specimens making them more porous and therefore more exposed to external influences. As it was expected and already shown by other researchers [17] the specimens printed with smaller layer height had higher structural strength.

What is interesting to notice however, is that although heat treatment of the specimens showed to be beneficial in almost all cases, it was a little more effective for the $0.3 \mathrm{~mm}$ layer specimens. The average increase in strength for the new specimens was around $4 \%$ for the $0.1[\mathrm{~mm}]$ and $4.5 \%$ for those printed with $0.3[\mathrm{~mm}]$. The printing orientation was influential for the heat treatment as well, with the average increase of strength for the new samples ranging from less than $2 \%$ for the $45 /-45$ combinations (Figure 11-a) up to more than $8 \%$ for the 0/30/-30/-60/60/90 combinations (Figure 11-c).

One of the authors intentions was to examine the influence of heat treatment on the aging process of the PLA material. It can be seen that heat treating the specimens (both aged and new) printed with 0.1 $[\mathrm{mm}]$ layer height almost annulled the aging degradation with average decrease of strength of less than $1 \%$ compared to almost $7 \%$ decrease in the untreated specimens. Unexpectedly, the heat treatment of the $0.3[\mathrm{~mm}]$ layer specimens on average did not slow down the material degradation but hastened it. The average decrease in strength for all untreated $0.3 \mathrm{~mm}$ specimens was around $23 \%$ while for the heat treated was almost 26\%. It is unclear why is this happening. Perhaps the additional exposure to heat made the material more susceptible to external influence or the larger "free space" allowed for an increase of the observed irregularities through the heat treatment. It is the authors opinion that this 
phenomenon should be additionally examined with PLA filaments from different manufacturers as well as with other type of materials (ABS, PET-G etc.). This effect could be attributed to the large variability and inconsistency of PLA printed parts due to material anisotropy [18] but it is unlikely since this behavior was observed in most specimens. It should be mentioned that one specimen from batches 16, $17,18,22,23$ and 24 (six in total) were removed from the analysis due to the extreme discrepancy in obtained values.
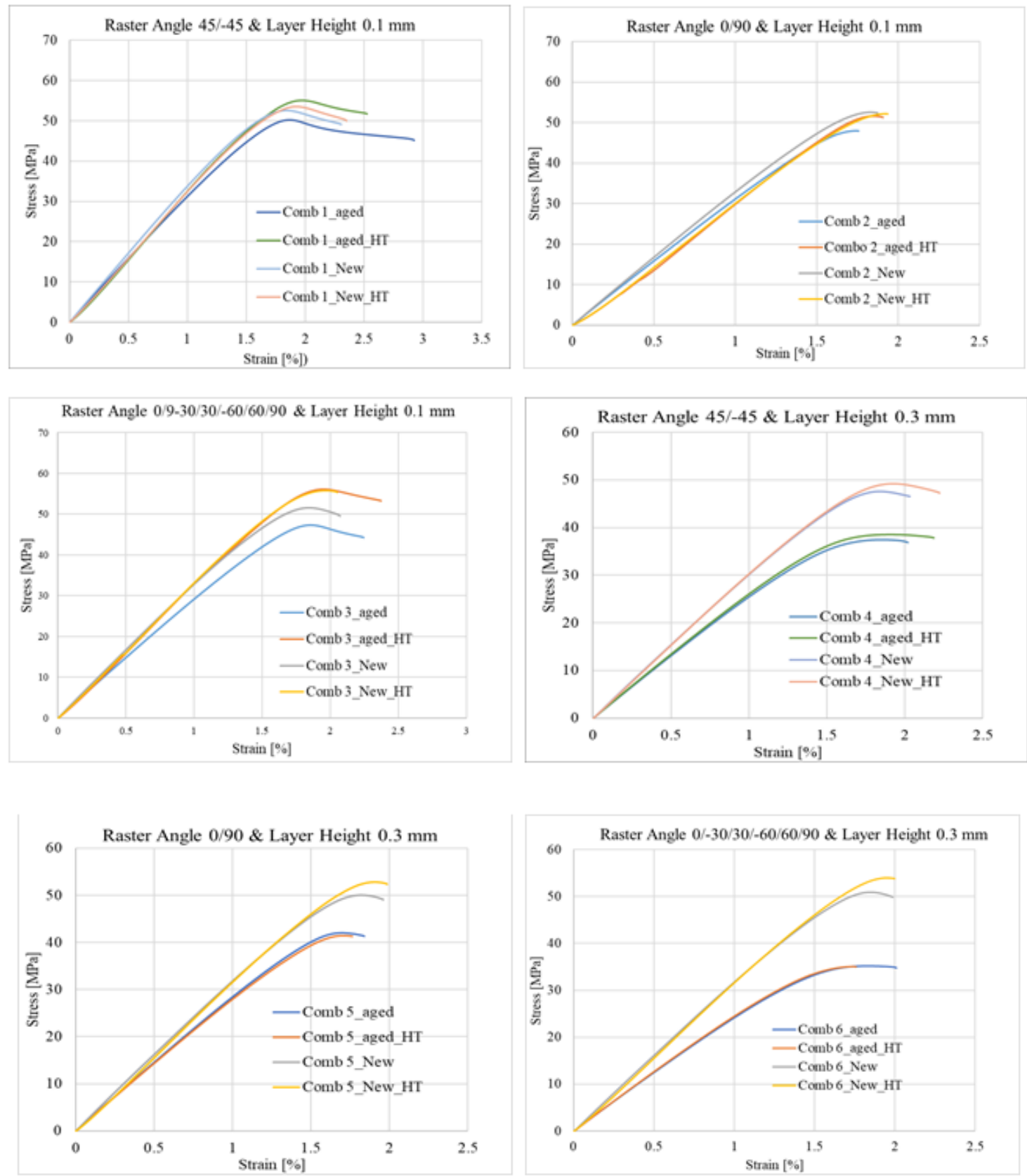

Figure 12: Averaged stress-strain curves

The averaged stress strain curves for all tested combinations are shown in Figure 12. The influence of printing orientation can be seen from the stress-strain curves as well. It can be noticed that the behavior of the $\left.0 / 90{ }^{\circ}\right]$ printed orientation specimens is almost linear and has the smallest elongation at break hence it is the most brittle of the considered orientations. The 45/-45 [ ${ }^{\circ}$ ] orientation has the highest average elongation and the highest plasticity. 


\section{Conclusions}

The impact of aging and heat treatment on the mechanical properties of PLA filament printed parts was analyzed via experimental testing. It was observed that with aging the mechanical properties of the PLA parts degrade and are more expressed when the printing resolution is lower i.e. with higher layer height. It was also interesting to see the reduction in elastic modulus introduced by aging in the $0.3 \mathrm{~mm}$ layer specimens since it implies that almost the same deformation can be obtained with noticeably smaller force. The influence in printing orientation on the plasticity of the specimens has been shown with the $0 / 90\left[^{\circ}\right]$ being the most brittle and the $-45 / 45\left[^{\circ}\right]$ withstanding the highest deformations before break.

Though heat treatment improves the strength of the specimens, oddly enough it was seen that while it slows down the degradation process in the $0.1 \mathrm{~mm}$ specimens it hastens it in the $0.3 \mathrm{~mm}$ specimens.

The obtained results should be approached conservatively since there is a lot of uncertainty due to material anisotropy as well as local influence of imperfections introduced by the printing process. Some of these imperfections and their influence were observed by the investigation carried out using a microscope and are emphasized here as well.

It was considered beneficial to conduct the experiments on mechanical parts produced by a consumer- grade printer and a widely available filament in order to give designers and hobbyists with limited resources an insight into the behavior of parts printed by this kind of printing process.

Acknowledgments: This work was financially supported by the Ministry of Education, Science and Technological Development (Serbia). (Grants No. 451-03-68/2020-14/200105 and 451-03-68/202014/200026).

\section{References}

1. NGO, TD., KASHANI, A., IMBALZANO, G., NGUYEN, KTQ., HUI, D., Additive Manufacturing (3d Printing): A Review of Materials, Methods, Applications And Challenges. Composites Part B Eng., 143, 2018,172-196. https://doi.org/10.1016/j.compositesb.2018.02.012

2. ALAFAGHANI, A., QATTAWI, A., ALRAWI, B., GUZMAN, A., Experimental Optimization of Fused Deposition Modelling Processing Parameters: A Design-for-Manufacturing Approach. Procedia Manufacturing, 10, 2017, 791-803. http://dx.doi.org/10.1016/j.promfg.2017.07.079

3. UDDIN, MS., SIDEK, MFR., FAIZAL, MA., GHOMASHCHI, R., PRAMANIK, A., Evaluating Mechanical Properties and Failure Mechanisms of Fused Deposition Modeling Acrylonitrile Butadiene Styrene Parts. Journal of Manufacturing Science and Engineering, Transactions of the ASME, 139(8), 2017, 1-12.

4. TAO, Y., WANG, H., LI, Z., LI, P., SHI, SQ., Development and Application of Wood Flour-Filled Polylactic Acid Composite Filament for 3D Printing. Materials, 10(4), 2017, 1-6.

5. ES-SAID, OS., FOYOS, J., NOORANI, R., MENDELSON, M., MARLOTH, R., PREGGER, BA., Effect of Layer Orientation on Mechanical Properties of Rapid Prototyped Samples. Materials and Manufacturing Process, 15(1), 2000, 107-122.

6. LIAO, G., LI, Z., CHENG, Y., Properties of Oriented Carbon Fiber/Polyamide 12 Composite Parts Fabricated by Fused Deposition Modeling. Materials and Design, 139, 2018, 283-292.

7. AFROSE, MF., MASOOD, SH., IOVENITTI, P., NIKZAD, M., SBARSKI, I., Effects of Part Build Orientations on Fatigue Behaviour of FDM-Processed PLA Material. Progress in Additive Manufacturing. 1(1-2), 2016, 21-28.

8. FERNANDES, J., DEUS, A. M., REIS, L., VAZ, M. F., \& LEITE, M., Proceedings Of the 3rd Internatioal Conference on Progress in Additive Manufacturing (Pro-AM 2018), 547-552.

9. FERNANDEZ-VICENTE, M., CALLE, W., FERRANDIZ, S., CONEJERO, A., Effect of Infill Parameters on Tensile Mechanical Behavior in Desktop 3D Printing. 3D Printing and Additive Manufacturing, 3(3), 2016, 183-192. 
10. WU, W., GENG, P., LI, G., ZHAO, D., ZHANG, H., ZHAO, J., Influence of Layer Thickness and Raster Angle on The Mechanical Properties of 3D-Printed Peek and a Comparative Mechanical Study Between PEEK and ABS. Materials (Basel), 8(9), 2015, 5834-5846.

11. DOBRESCU, T., PASCU, NE., JIGA, G., et al. Tensile Behavior of PLA and PLA Composite Materials Under Different Printing Parameters. Mater. Plast., 56(4), 2019, 783-800.

12. YU, L., LIU, H., XIE, F., CHEN, L., LI, X., Effect of Annealing and Orientation on Microstructures and Mechanical Properties of Polylactic Acid. Polymer Engineering \& Science, 48(4), 2008, 634-641

13. ***ASTM D638- 14. Standard Test Method for Tensile Properties of Plastics. ASTM International, West Conshohocken, PA, 2014

14.*** Ultimaker Cura. Available online: https://ultimaker.com/software/ultimaker-cura. Accessed March 26, 2020.

15.***Sterilizator-suhi, Available online: https://www.festta.hr/proizvod/sterilizator-suhi-tip-st-0102/. Accessed April 1, 2020.

16.*** Testo 735-2 Multichannel thermometer. Available online: https://www.testo.com/en-US/testo735-2/p/0563-7352. Accessed April 1, 2020.

17. GEBISA, AW., LEMU, HG., Influence of 3D Printing FDM Process Parameters on Tensile Property Of Ultem 9085. Procedia Manuf, 30(May), 2019, 331-338.

18. BANJANIN, B., VlADIĆ, G., PÁL, M. BALOS, S., DRAMICANIN, M., RACKOV, M., KNETEVIC, I., Consistency Analysis of Mechanical Properties of Elements Produced by FDM Additive Manufacturing Technology. Materia (Rio de Jenerio), 23(4),2018.

Manuscript received: 16.04 .2020 